\title{
Anticipatory Grief Among Close Relatives of Patients with ALS and MS
}

\author{
Agneta Grimby, Åsa K. Johansson, Ulf Johansson \\ Department of Medicine, Sahlgrenska Academy, Gothenburg University, Gothenburg, Sweden
}

\section{Email address:}

agneta.grimby@telia.com (A. Grimby)

\section{To cite this article:}

Agneta Grimby, Åsa K. Johansson, Ulf Johansson. Anticipatory Grief Among Close Relatives of Patients with ALS and MS. Psychology and Behavioral Sciences. Vol. 4, No. 3, 2015, pp. 125-131. doi: 10.11648/j.pbs.20150403.16

\begin{abstract}
A postal survey was sent to close relatives of Swedish patients with ALS and progressive MS to assess preparatory grief according to the Anticipatory Grief Scale (AGS), together with age, relationship, duration of the illnesses, perceived quality of care, present need of care, caregiver burden, and need of support. The relatives in the two illness groups generally responded in similar ways on the AGS, e.g. reporting closeness, preoccupation, tearfulness, and feelings of injustice regarding the illness. More MS relatives agreed on being irritable and wondering about life without the disease; they reported increased competence, but less ability to move ahead with life. The relatives' need to talk to somebody outside the family and the hospital staff was more frequently reported by the MS relatives than by the ALS relatives. Overall, the need to talk correlated to feelings of loneliness, longing, tearfulness, loss of interest in daily activities, worries for the future, irritability and sleeping problems. However, surprisingly many of the ALS and MS relatives reported planning for the future and had discovered new personal resources after the diagnose, possibly indicating an overweight of responders adjusted to the situation and therefore expressing less sorrow.
\end{abstract}

Keywords: Anticipatory Grief, ALS, MS, Close Relatives, Need of Care, Caregiver Burden, Support

\section{Introduction}

Caregiver burden among primary caregivers of seriously ill patients with ALS (amyotrophic lateral sclerosis) and MS (multiple sclerosis) is a complex construct mostly involving the caregiver's emotional and physical health and social life (O'Doherty et al 2010). The quality of life and the management of chronic sorrow in families of ALS and MS patients are increasingly discussed in terms of psychosocial stress, anxiety, depression and a pervasive sadness that can be permanent, periodic, and progressive in nature (Hainsworth 1995; Bolmsjö \& Hermerén 2001; Trail et al 2004; Isaksson \& Ahlström 2008; Vignola et al 2008; Olsson et al 2011; Pagnini 2013; Lillo et al 2013; Tramonti et al 2014).

\subsection{ALS}

Amyotrophic lateral sclerosis (ALS) is a rapidly progressive, invariably fatal neurodegenerative disease that attacks the nerve cells responsible for controlling voluntary muscles. It has a strong impact on the lives of the affected people and their close relatives, who have to tackle the demanding duties of caring for and assisting them. Neurobehavioral symptoms are common among ALS patients and are found to have a profound negative impact on caregivers' psychological status facing a loved one suffer from a disease with a progressive and rapid course that, so far, cannot be stopped or reversed (Chio et al 2010; Pagnini 2013).

Often, close relatives take on the carers' duties, a burden mostly involving physical, psychological and social life changes. Low mood, anxiety, fear, and despair make the carers see their lives in terms of before or after the disease. Although the diagnosis is frightening, a tendency toward increasing levels of cohesion and adaptability may occur. Coping strategies, satisfaction with care-giving, and patient disease severity are said to play an essential role for the carers' quality of life, as also support offered by counseling groups and a well-equipped hospital staff. Caregivers' well being may also depend on disease progression, premorbid characteristics (e.g., personality or demographics), or idiosyncratic effects (e.g., life events unrelated to the disease), 
and also differ for patients and caregivers (Trail et al 2004; Roach et al 2009).

Compared with MS, ALS is a more uncommon disease with a relative short survival (Liao \& Arnold 2007). As carers in both groups are feeling uncertainty facing an unpredictable future, one can find an increasing number of studies on sorrow, depression and chronic grief (Öhman \& Söderberg 2003; Gauthier et al 2005; Vignola et al 2008; Rabkin et al 2009; Pagnini et al 2010; Olsson et al 2011; Lillo et al 2012; Pagnini et al 2012; Trail et al 2013; Chen et al 2015).

\section{2. $M S$}

Multiple sclerosis (MS) is an immune-mediated inflammatory disorder of the central nervous system (CNS) that is both chronic and debilitating (National Multiple Sclerosis Society; Definition of MS). Symptom presentation and severity can vary widely, but the majority of patients with MS will develop neurological disability and cognitive dysfunction over time. Whereas ALS is a relentlessly progressive and rapidly fatal condition, MS is a chronic condition generally progressing slowly and with occasionally remissions over a period of many years.

The disability associated with MS not only has an impact the patient's quality of life, but is also linked to their caregivers and families and society as a whole (Campbell et al 2014). The cause of MS is currently unknown, but immediate family history, low blood levels of vitamin $\mathrm{D}$, and cigarette smoking, among other factors, appear to increase the risk of developing MS (Maroney \& Hunter 2014). MS afflicts many people who have their most productive years ahead. Furthermore, the economic burden associated with MS can be considerable, especially when taking into account both direct costs (e.g. MS-specific healthcare) and indirect costs (e.g. lost ability to work) (Buhse 2008; Brandes et al 2010). MS can be disabling as early as 6 years after diagnosis with permanent disability often occurring within 10 years after diagnosis if not properly treated (Brandes et al 2010).

MS impacts the health-related quality of life (HRQL) in partners, but further knowledge on the longitudinal perspective is needed (Figved et al 2007). Caregivers of patients with MS experience high levels of distress and reduced quality of life. They are usually burdened with a wide range of caregiving tasks, which may result in damages of daily life and their quality of life (Ertekin et al 2014).

As lowered QL, increased sadness, anxiety, sorrow, depression and grief reactions are frequently reported by families of ALS and MS patients (Liedström et al 2008; Isaksson \& Ahlström 2008; Olsson et al 2011; Lillo et al 2012), we got interested in measuring the anticipatory grief according to a scale, which could be suited for this purpose. The Anticipatory Grief Scale (AGS) has been applied in assessments of grief reactions in relation to other diseases (Theut et al 1991; Marwit \& Meuser 2002; Marwit\& Meuser 2005; Liu \& Lai 2006; Holley \& Mast 2009; Johansson et al 2012; Fowler et al 2012; Johansson et al 2013; Johansson \& Grimby 2014), however, not to ALS and MS.

\section{Aim and Method}

\subsection{Aim}

The purpose of this study was to describe the outcome of AGS measurement among close relatives to persons suffering from ALS and MS, and to relate it to others' and our own studies on preparatory grief at severe illness (Figved et al 2007; Alshubaili et al 2007; Buhse 2008; Isaksson \& Ahlström 2008; Johansson \& Grimby 2012; Johansson et al 2013; Johansson et al 2014; Labiano-Fontcuberta et al 2014).

\subsection{Data Collection and Participants}

Caregivers of patients with ALS and MS were invited to participate in a survey about anticipatory grief by advertisements in the Swedish Neuro Association's magazine Reflex during 2014. The magazine is released six times a year. The caregivers were asked to respond to the project leader (A.G.) by mail or letter to receive a questionnaire, and to return it without their name, thereby keeping their identities anonymous.

The Anticipatory Grief Scale (AGS) (Theut et al 1991) is a 27-item self-administered questionnaire assessing reactions to and coping with expected death and can be completed in 10 to 15 minutes. The responses range from "Strongly disagree", "Disagree", "Somewhat agree, "Agree", and "Strongly agree". In the data analyzes, the answers were dichotomized into two steps "Agree" and "Disagree". The AGS scale represents the major domains cited in the literature on grief. It was intended for relatives of persons diagnosed with dementia, but the wording could be changed to other disease diagnosis, for example dementia, cancer, and Parkinson's disease (Theut et al 1991; Marwit \& Meuser 2002; Johansson \& Grimby 2012; Johansson et al 2013; Johansson \& Grimby 2014). The internal consistency of AGS using Cronbach alpha, the alpha level for the scale has been shown to be good at .84. The advantage of using the AGS is that clinicians, social workers, and counselors can identify the problems an individual may be experiencing before the death of the relatives, and that proper interventions can take place to avert long-term negative outcomes after the death.

Among the background variables were relationship (Spouse, Cohabitant, Sibling, Child, or Other), age of the respondent and the relative with ALS or MS, the duration of the disease (in the analyzes divided into 1-4 yrs, 5-9 yrs, 10$14 \mathrm{yrs}, 15-19 \mathrm{yrs}$ and $>20 \mathrm{yrs}$ ), the respondents' perceived quality of the present care of the relative (Very good, Good, Not so good, Rather bad, and Bad), the perceptions of the present daily health care need of the ALS and MS patient (Very extensive, Extensive, Not so extensive, Rather little, and Little). The estimations made by the respondents about their experience of caregiver burden ranged from Not actual (as the patient doesn't live at home), Very heavy, Heavy, Rather heavy, Rather easy, and Easy). Also the respondents' need to talk to somebody (outside the family and the hospital staff) was assessed (I already have someone to talk to; Not actual as I already have someone to talk to; No, I don't need 
to talk; and Yes, I need to talk). In the data analyzes, the responses at the separate items of the AGS (I strongly disagree, I disagree, I somewhat agree, I agree, I strongly agree) were dichotomized (I agree and I don't agree).

\subsection{Statistics}

Comparisons between characteristics of the 2 diagnostic groups were done with Fisher exact test. $\mathrm{P}<0.05$ was defined as statistically significant.

\subsection{Ethics}

All participants were informed about the purpose of the research, could freely ignore the questionnaire mailed by leader, did not write their name on any answer, were nor coded in any way on the envelope, and were therefore ensured anonymity also in the published work. The study is a part of the longitudinal Grief Project at Sahlgrenska University Hospital that has been approved by the Ethical Committee of the University of Gothenburg (Dnr 253-95).

\section{Results}

Totally 103 relatives of ALS and MS patients accepted the invitation to participate in this postal survey evaluating anticipatory grief according to AGS. The caregivers who agreed to participate and returned the questionnaire were 99 (96\%). Of them, 5 did not continue the study, some were invalid $(n=3)$ and some were returned blank $(n=2)$. Data from the ALS and MS caregivers of totally 89 patients $(86 \%)$ was found valid for statistical purposes.
The overall mean age of the ALS and MS patients was 59.4 yrs, median $61.0 \mathrm{yrs}$, SD $11.2 \mathrm{yrs}$. The mean age of the ALS patients was $61.4 \mathrm{yrs}$, median $61.5 \mathrm{yrs}$, SD $11.1 \mathrm{yrs}$. The mean age of the MS patients was $57.8 \mathrm{yrs}$, median $61.0 \mathrm{yrs}$, SD 11.2 yrs.

The overall mean age of the ALS and MS caregivers was 58.7 yrs $(\mathrm{SD}=12.1 \mathrm{yrs}$, median $61.0 \mathrm{yrs})$. Ten per cent was younger than 40 yrs of age, 54\% was aged 40-65 yrs, and $36 \%$ over age $65 \mathrm{yrs}$ (difference $\mathrm{p}=0.0165$ ). The age difference between the relatives of the ALS and MS patients was not significant.

In terms of relationship to the patient, $61 \%(n=53)$ were spouses or partners, $16 \%(\mathrm{n}=14)$ was offspring, siblings $8 \%$ $(n=7), 14 \%(n=12)$ were parents, and $3 \%(n=3)$ were other relatives. Ten per cent were under $40 \mathrm{yrs}, 54 \%$ were between 40-65 yrs, and 36\% were over 65 yrs.

Reports on the duration of the ALS and MS illnesses differed significantly $(\mathrm{p}=0.0001)$. The average ALS duration was 9.4 yrs, median $3.0 \mathrm{yrs}$, SD $10.4 \mathrm{yrs}$, and the average MS duration 18.0 yrs, median 15.0 yrs, SD 9.2 yrs. Table 1 presents the data and a graph (Figure 1) according to percentages regarding the intervals of years.

Table 1. Reports on the duration of the ALS and MS illnesses in the study.

\begin{tabular}{llllll}
\hline \multirow{2}{*}{ Disease } & \multicolumn{5}{l}{ Years of duration } \\
\cline { 2 - 6 } & $\mathbf{1 - 4}$ & $\mathbf{5 - 9}$ & $\mathbf{1 0 - 1 4}$ & $\mathbf{1 5 - 1 9}$ & $\mathbf{2 0}-$ \\
\hline ALS \% & 59.0 & 7.7 & 7.7 & 5.1 & 20.5 \\
MS \% & 0.0 & 12.2 & 30.6 & 14.3 & 42.9 \\
\hline
\end{tabular}

\section{Per cent}

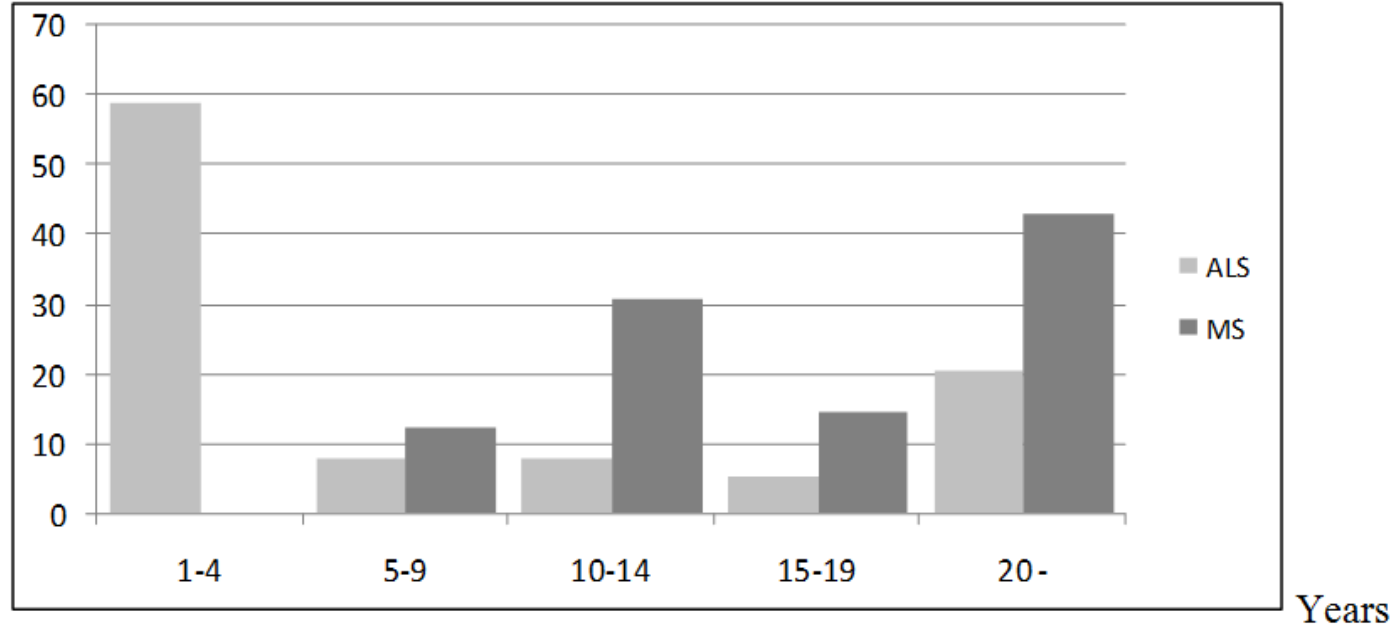

Figure 1. Diagram of the reports (\%) on the duration (years) of the ALS and MS illnesses in the study.

\subsection{AGS Reports}

Significant differences between the respondents in the ALS and MS groups existed for 4 items of the AGS (Table 2): I seem to be more irritable since the diagnosis was made for my relative (more in the MS group, $\mathrm{p}=0.01786$ ), I wonder what my life would be like if my relative had not been diagnosed with ALS or MS (more in the MS group, $\mathrm{p}=0.00807$ ), I am able to move ahead with my life (more in the ALS group, $\mathrm{p}=0.01292$ ), and I feel more competent since my relative was diagnosed with ALS or MS (more in the MS group, $\mathrm{p}=0.00350$ ).

Very negative but also less or moderately negative AGS reports were found among the relatives of the ALS and MS 
patients. Preoccupation with and tearfulness when thinking of the course of the illness, missing past times, the loss of togetherness and feelings of injustice due to the illness were frequent negative reactions and thoughts. Positively, however, almost all relatives reported that they felt close to the ill person, many had adjusted to the illness, had personal resources to cope with the future, were able to move ahead with their lives, and were planning for the future. Many stated that they had a need to talk to others about the illness, felt alone, and daydreamed about life before the illness.
However, half of the respondents stated that they were functioning about as well as before the relative was diagnosed with ALS or MS. Rather many (about one of four) felt angry about the situation, found it hard to accept the diagnose (ALS 42\% and MS 29\%), and had sleeping problems, but about equally many had discovered new personal resources after the diagnose. Few felt detached from the ill person, avoided other people since the diagnose, and felt uninterested in daily news. Few relatives blamed themselves for the illness.

Table 2. Results on the Anticipatory Grief Scale (AGS) of 39 relatives of persons with ALS and 50 relatives of persons with MS.

\begin{tabular}{|c|c|c|}
\hline & \multicolumn{2}{|c|}{ Agree (\%) } \\
\hline & \multicolumn{2}{|c|}{ Relatives of persons with } \\
\hline & ALS & MS \\
\hline 1. I daydream about how life with my relative was before the diagnosis of illness was made. & 54 & 47 \\
\hline 2. I feel close to my relative who has ALS or MS. & 100 & 96 \\
\hline 3. I seem to be more irritable since the diagnosis was made for my relative. & 16 & $41 *$ \\
\hline 4. I am preoccupied with thoughts about my relative and his or her illness. & 68 & 69 \\
\hline 5. I have discovered new personal resources since my relative's illness was diagnosed. & 26 & 31 \\
\hline 7. I seem to be more irritable since the diagnosis was made for my relative. & 26 & 42 \\
\hline 8. I am able to move ahead with my life. & 82 & $56^{*}$ \\
\hline 9. I blame myself for my relative's illness. & 3 & 4 \\
\hline 10. I find it hard to concentrate on my work since the diagnosis was made for my relative. & 21 & 18 \\
\hline 11. I have the personal resources to help me cope with my relative and his or her illness. & 81 & 78 \\
\hline 12. I have periods of tearfulness as I think about the course of my relative's illness. & 80 & 63 \\
\hline 13. I feel detached from my relative. & 13 & 14 \\
\hline 16. I find it hard to sleep since the diagnosis was made for my relative. & 28 & 20 \\
\hline 17. No one will ever take the place of my relative in my life. & 76 & 58 \\
\hline 18. I avoid some people since my relative was diagnosed with ALS or MS. & 8 & 12 \\
\hline 19. I feel I have adjusted to my relative's illness. & 90 & 94 \\
\hline 20. Since my relative was diagnosed with ALS or MS, I find it more difficult to get along with certain people. & 10 & 12 \\
\hline 21. I wonder what my life would be like if my relative had not been diagnosed with ALS or MS. & 44 & $74 * *$ \\
\hline 22. I feel more competent since my relative was diagnosed with ALS or MS. & 19 & $50 * *$ \\
\hline 23. I get angry when I think about my relative having ALS or MS. & 27 & 25 \\
\hline $\begin{array}{l}\text { 24. Since the diagnosis was made for my relative, I don't feel interested in keeping up with the day-to-day activities (TV, } \\
\text { newspapers, and friends). }\end{array}$ & 8 & 12 \\
\hline 25. I am unable to accept the fact that my relative has a diagnosis of ALS or MS. & 42 & 29 \\
\hline 26. I am now functioning about as well as before my relative was diagnosed. & 62 & 52 \\
\hline 27. I am planning for the future. & 68 & 67 \\
\hline
\end{tabular}

$*$ Refers to $\mathrm{p}<0.05, * *$ refers to $\mathrm{p}>0.01$, significant difference between the two study groups

\subsection{Correlations}

Totally $49 \%$ of the ALS and MS relatives experienced the caregiver burden as heavy, $21 \%$ as rather heavy and $31 \%$ as easy. These differences were not significant, nor were the differences when dividing the relatives into spouses and others. The various categories of relatives (spouse, parent, sibling, child, and other) were not significantly related to the experience of caregiver burden, nor to the perceived quality of care.

The relatives of the ALS and MS groups reported the experience of caregiver burden in similar ways. The reports on high burden seemed to increase with age of the respondents, however not significantly. Neither did the reports on the number of years suffering from the disease correlate with caregiver burden. The perceived quality of the present care of the relative was also similar, as the perceptions of the present daily health care need of the ALS and MS patients.

The experience of caregiver burden was not related to the relatives' age or illness category (ALS or MS). When the caregiver burden was assessed to be heavy, the burden seemed to increase (not significantly) from under forty to the years over sixty-five.

The relatives' need to talk to somebody outside the family and the hospital staff was more reported by the relatives of the MS' than the ALS' patients (58\% and 39\% respectively, $\mathrm{p}=0.0522$ ). "I already have someone to talk to" was reported by $36 \%$ of the ALS, compared to $20 \%$ of the MS relatives' group (ns). No, I don't need to talk was reported by $26 \%$ ALS and 22\% MS relatives (ns).

Reports on "I need to talk to someone outside the family and the ward staff " was related with several of the AGS items. These were: I daydream about how life with my 
relative was before the diagnosis of illness was made $(\mathrm{p}=0.0080)$; I seem to be more irritable since the diagnosis was made for my relative ( $\mathrm{p}=0.0005)$; I very much miss my relative the way he or she used to be $(\mathrm{p}=0.0259)$; I have felt very much alone since the diagnosis was made for my relative $(\mathrm{p}=0.0001)$; I am able to move ahead with my life $(p=0.0021)$; I have periods of tearfulness as I think about the course of my relative's illness $(p=0.0416)$; I feel a need to talk to others regarding my relative's illness $(p=0.0030)$; I find it hard to sleep since the diagnosis was made for my relative $(p=0.0014)$, and Since the diagnosis was made for my relative, I don't feel interested in keeping up with the day-to-day activities $(\mathrm{p}=0.0439)$.

The total number of AGS items of negative character/"worse adjustment" was larger among those who acknowledged the AGS item I feel a need to talk to others regarding my relative's illness. This item was related to some other AGS items: I daydream about how life with my relative was before the diagnosis of illness was made $(p=0.0442)$, I seem to be more irritable since the diagnosis was made for my relative $(p=0.0045)$, and I get angry when I think about my relative having ALS or MS $(\mathrm{p}=0.0283)$.

The reports on Quality of care were not significantly related to the AGS items of negative character/"worse adjustment", or to the Experience of caregiver burden.

Among the AGS items related to "better adjustment" were: I am planning for the future $(p=0.0043)$, and I have discovered new personal resources since my relative's illness was diagnosed $(p=0.0063)$.

\section{Discussion}

The postal survey among relatives of eighty-nine Swedish patients suffering from ALS and progressive MS showed an overall distress by the situation. The Anticipatory Grief Scale (AGS) with items to a larger part of emotional character has been used in several other studies to measure preparatory grief reactions among family members of patients with fatal diseases (Theut et al 1991; Liu \& Lai 2006; Johansson \& Grimby 2012; Johansson et al 2013; Johansson \& Grimby 2014). Preoccupation with the ill relative, worries over the past and the future, the experiences of caregiver burden, sadness, loneliness, acceptance of the situation and a need to talk about the situation were present also in this study.

Compared to other studies on the ALS and MS diseases (Millul et al 2005; Czaplinski et al 2006; Kingwell et al 2013; Wolf et al 2014; Stellman et al 2014; McKay et al 2015), the duration of the both illnesses seemed more extensive than usual. Half of the relatives reported a heavy caregiver burden regardless their age or the relative's illness. Other studies on caregiver burden have more in detail assessed psychosocial factors as well as physical, economical and gender ones (Trail et al 2004; Confavreux \& Vucusic 2006; Buhse 2008; Montel et al 2012; Pike et al 2012). We wanted the questionnaire to be convenient and not dispatched by the responders of that reason, which might be a limitation to the study.

The possibilities to have someone to talk to about the illness situation seemed frequent and urgent in both groups of relatives. Surprisingly, the MS relatives seemed to have a more eager need to talk to someone outside the family and hospital staff than the ALS. Among possible explanations may be that ALS families in Sweden could be offered earlier and better support opportunities by both hospital and community. (The reason and the subject of this need were, however, not investigated in this study. If there would be medical or practical problems to discuss, the staff at the hospital would be preferred). The finding could also be an effect of limitations in the number of responders and the place of living being from various parts of Sweden. Some mails and letters to the project leader (A.G.) told stories exposing great sorrow, anxiety and despair. Anyhow, a recommended question to be asked at the time of diagnosis would be, if the relatives have an unmet need to talk - inside or outside the hospital - both at MS and ALS.

Grief and depression support is demonstrated to be efficient and preventive regarding relatives' maladjustment and excessive sorrow in both ALS and MS, the earlier the better, and preferably on both individual bases and together in pairs and involved in the planning of care (Olsson et al 2011; Gottberg et al 2014), and especially when the carer is stressed by e.g. behavioral changes and physical disability in ALS (Lillo et al 2012).

It has been demonstrated that if problem behaviour exists, carers participate more often in support groups, preferably as soon as possible to decrease the burden of the carer (Bolmsjö \& Hermerén 2001; Hecht et al 2003; Chio et al 2010). Relatives' need of someone in whom they can confide is found in both ALS and MS, especially when mental and physical health impacts the QL, and the sorrow might become chronic (Figved et al 2007; Buhse 2008; Johansson et al 2012; Alshubaili et al 2007; Isaksson \& Ahlström 2008; Jongen et al 2014; Labiano-Fontcuberta et al 2014). According to Labiano-Fontcuberta and coworkers (2015) clarification may help identify improved supportive strategies for both caregivers and patients with MS, which also would work well at ALS. As emotional factors and the disability of the person with MS and ALS in fact are major predictors of burden, psychological and social support should be considered to reduce caregiver burden (Rivera-Navarro et al 2009).

Still, to a surprisingly large extent, the relatives of both ALS and MS seemed to function well and to plan for the future. As many stated that "I am able to move ahead with my life and will have adjusted to my relative's illness", there might be a bias in the selection of responders. Have the more part of the responders only included the well adjusted, i.e. those without depression and chronic sorrow, answered the survey? The almost totally reported closeness to the ill person may also suggest some bias in the selection or a misinterpretation of this item. On the other hand, researchers have found a tendency toward patterns of extreme family functioning with increasing levels of cohesion and adaptability. Increasing and extreme levels of both cohesion and adaptability seem to be expected and even adaptive in the 
case of a progressive and impairing disease like ALS (Tramonti et al 2014).

\section{Acknowledgments}

Thanks are due to all those who have helped us answering the questionnaires. We are also grateful to Valter Sundh, BSc, for statistical discussions and invaluable help with the data processing.

\section{Funding}

The authors disclosed receipt of the following financial support for the research, authorship, and/or publication of this article. This research was facilitated by grants from the Swedish Neuro Association.

\section{References}

[1] Alshubaili AF, Awadalla AW, Ohaeri JU, Mabrouk AA. Relationship of depression, disability, and family caregiver attitudes to the quality of life of Kuwaiti persons with multiple sclerosis: a controlled study. BMC Neurol 2007; 18: 7-31.

[2] Berg J, Lindgren P, Fredrikson S, Kobelt G. Costs and quality of life of multiple sclerosis in Sweden. Eur J Health Econ 2006; 7 Suppl 2: 75-85.

[3] Bolmsjö I, Hermerén G. Interviews with patients, family, and caregivers in amyotrophic lateral sclerosis: comparing needs. $J$ Palliat Care 2001; 17: 236-240.

[4] Brandes DW, Shaya FT, Pill MW. Quantifying the Role of Natalizumab in Health and Economic Outcomes in Multiple Sclerosis. Am J Manag Care 2010; 16: 171-177.

[5] Buhse M. Assessment of caregiver burden in families of persons with multiple sclerosis. J Neurosci Nurs 2008; 40: 2531 .

[6] Campbell JD, Ghushchyan V, McQueen RB, et al. Burden of multiple sclerosis on direct, indirect costs and quality of life: national US estimates. Mult Scler Relat Disord 2014; 3: 227 236.

[7] Chen D, Guo X, Zheng Z, Wei Q, Song W, Cao B, Huang R, Yang R, Shang H. Depression and anxiety in amyotrophic lateral sclerosis: Correlations between the distress of patients and caregivers. Muscle Nerve 2015; 51:353-357.

[8] Chio A, Vignola A, Mastro E, Giudici AD, Iazzolino B, Calvo A, Moglia C, Montuschi A. Neurobehavioral symptoms in ALS are negatively related to caregivers' burden and quality of life. Eur J Neurol 2010; 17: 1298-1303.

[9] Confavreux C, Vukusic S. Age at disability milestones in multiple sclerosis. Brain 2006; 129: 595-605.

[10] Czaplinski A, Yen AA, Appel SH. Amyotrophic lateral sclerosis: early predictors of prolonged survival. J Neurol 2006; 253: 1428-1436.

[11] Ertekin Ö, Özakbaz S, Idiman E. Caregiver burden, quality of life and walking ability in different disability levels of multiple sclerosis. NeuroRehabilitation 2014; 34: 313-321.
[12] Figved N, Myhr KM, Larsen JP, Aarsland D. Caregiver burden in multiple sclerosis: the impact of neuropsychiatric symptoms. J Neurol Neurosurg Psychiatry 2007; 78: 1097-1102.

[13] Fowler NR, Hansen A, Garand L. Association between anticipatory grief and social problem solving among caregivers. J Aging Health 2013; 25: 493-509.

[14] Gauthier A, Vignola A, Calvo A, Cavallo E, Moglia C, Sellitti L, Mutani R, Chiò A. A longitudinal study on quality of life and depression in ALS patient-caregiver couples. Neurology 2007; 68:923-926.

[15] Gottberg K, Chruzander C, Einarsson U, et al. Health-related quality of life in partners of persons with MS: a longitudinal 10-year perspective. BMJ Open 2014; 4:e006097.

[16] Hainsworth MA. Helping spouses with chronic sorrow related to multiple sclerosis. J Gerontol Nurs 1995; 21: 29-33.

[17] Hecht MJ, Graesel E, Tigges S, Hillemacher T, Winterholler M, Hilz MJ, Heuss D, Neundörfer B. Burden of care in amyotrophic lateral sclerosis. Palliat Med 2003 Jun; 17: 327333.

[18] Holley CK, Mast BT. The impact of anticipatory grief on caregiver burden in dementia caregivers. Gerontologist 2009; 49: 388-396.

[19] Isaksson AK, Ahlström G. Managing chronic sorrow: experiences of patients with multiple sclerosis. J Neurosci Nurs 2008; 40: 180-191.

[20] Johansson ÅK, Grimby A. Anticipatory Grief Among Close Relatives of Patients at Hospice and Palliative Wards. $\mathrm{Am} J$ Hosp Pall Med 2012; 29: 134-138.

[21] Johansson ÅK, Sundh V, Wijk H, Grimby A. Anticipatory grief among close relatives of persons with dementia in comparison with close relatives of patients with cancer. $\mathrm{Am} \mathrm{J}$ Hosp Palliat Care 2013; 30: 29-34.

[22] Johansson UE, Grimby A. Anticipatory Grief among Close Relatives of Patients with Parkinson's Disease. Psychol Behav Sci 2014; 3: 179-184.

[23] Jongen PJ, Ruimschotel R, Heerings M, Hussaarts A, Duyverman L, van der Zande A, Valkenburg-Vissers J, Wolper H, van Droffelaar M, Lemmens W, Donders R, Visser LH. Improved self-efficacy in persons with relapsing remitting multiple sclerosis after an intensive social cognitive wellness program with participation of support partners: a 6-months observational study. Health Qual Life Outcomes 2014; 19: 1240.

[24] Kingwell E, Marriott JJ, Jetté N. Incidence and prevalence of multiple sclerosis in Europe: a systematic review. $B M C$ Neurology 2013; 13: article 128.

[25] Koch M, Kingwell E, Rieckmann P, Tremlett H. The natural history of primary progressive multiple sclerosis. Neurology 2009; 73: 1996-2002.

[26] Labiano-Fontcuberta A, Mitchell AJ, Moreno-García S, Benito-León J. Anxiety and depressive symptoms in caregivers of multiple sclerosis patients: The role of information processing speed impairment. J Neurol Sci 2015; 349: $220-225$. 
[27] Labiano-Fontcuberta A, Mitchell AJ, Moreno-García S, Benito-León J. Cognitive impairment in patients with multiple sclerosis predicts worse caregiver's health-related quality of life. Mult Scler 2014; 20:1769-1779.

[28] Liu NC, Lai EYL. Find a way out: bereavement support in Taiwan hospice. Support Care Cancer 2006; 14: 4-10.

[29] Liao S, Arnold RM. Attitudinal Differences in Neurodegenerative Disorders. J Pall Med 2007; 10: 430-432.

[30] Liedström E, Isaksson AK, Ahlström G. Chronic sorrow in next of kin of patients with multiple sclerosis. J Neurosci Nurs 2008; 40: 304-311.

[31] Lillo P, Mioshi E, Hodges JR. Caregiver burden in amyotrophic lateral sclerosis is more dependent on patients behavioral changes than physical disability: a comparative study. BMC Neurol 2012; 12: 156.

[32] Maroney M, Hunter SF. Implications for Multiple Sclerosis in the Era of the Affordable Care Act: A Clinical Overview. Am J Manag Care 2014; 20: 220-227.

[33] Marwit SJ, Meuser TM. Development and initial validation of an inventory to assess grief in caregivers of persons with Alzheimer's disease. Gerontologist 2002; 42: 751-765.

[34] Marwit SJ, Meuser TM. Development of a short form inventory to assess grief in caregivers of dementia patients. Death Stud 2005; 29: 191-205.

[35] McKay KA, Kwan V, Duggan T, Tremlett H. Risk Factors Associated with the Onset of Relapsing-Remitting and Primary Progressive Multiple Sclerosis: A Systematic Review. BioMed Res Internat 2015; Article ID 817238.

[36] Millul A, Beghi E, Logroscino G, Micheli A, Vitelli E, Zardi A: Survival of patients with amyotrophic lateral sclerosis in a population-based registry. Neuroepidemiol 2005; 25: 114-119.

[37] Montel S, Albertini L, Desnuelle C, Spitz E. Evolution of quality of life, mental health, and coping strategies in amyotrophic lateral sclerosis: a pilot study. J Palliat Med 2012; 15:1181-1184.

[38] O'Doherty LJ, Hickey A, Hardiman O. Measuring life quality, physical function and psychological well-being in neurological illness. Amyotroph Lateral Scler 2010; 11: 461468 .

[39] Olsson Ozanne AG, Strang S, Persson L. Quality of life, anxiety and depression in ALS patients and their next of kin. $J$ Clin Nurs 2011; 20: 283-291.

[40] Pagnini F, Rossi G, Lunetta C, Banfi P, Castelnuovo G, Corbo $\mathrm{M}$, Molinari E. Burden, depression, and anxiety in caregivers of people with amyotrophic lateral sclerosis. Psychol Health Med 2010; 15: 685-693.
[41] Pagnini F. Psychological wellbeing and quality of life in amyotrophic lateral sclerosis: a review. Int J Psychol 2013; 48: 194-205.

[42] Pike J, Jones E, Rajagopalan K, Piercy J, Anderson P. Social and economic burden of walking and mobility problems in multiple sclerosis. BMC Neurol 2012; 12: 94.

[43] Rabkin, J G, Albert SM, Rowland LP, Mitsumoto H. How common is depression among ALS caregivers? Amyotroph Lateral Scler 2009; 10: 448-455.

[44] Rivera-Navarro J1, Benito-León J, Oreja-Guevara C, Pardo J, Dib WB, Orts E, Belló M. Caregiver Quality of Life in Multiple Sclerosis (CAREQOL-MS) Study Group. Burden and health-related quality of life of Spanish caregivers of persons with multiple sclerosis. Mult Scler 2009; 15: 13471355.

[45] Roach AR, Averill AJ, Segerstrom SC, Kasarskis EJ. The dynamics of quality of life in ALS patients and caregivers. Ann Behav Med 2009; 37: 197-206.

[46] Rotstein Z, Hazan R, Barak Y, Achiron A. Perspectives in multiple sclerosis health care: special focus on the costs of multiple sclerosis. Autoimmun Rev 2006; 5: 511-516.

[47] Stellmann JP, Neuhaus A, Lederer C, Daumer M, Heesen C. Validating Predictors of Disease Progression in a Large Cohort of Primary-Progressive Multiple Sclerosis Based on a Systematic Literature Review. PloS One 2014; 9:e92761.

[48] Theut SK, Jordan L, Ross LA, Deutsch SI. Caregiver's anticipatory grief in dementia: a pilot study. Int J Aging Hum Develop 1991; 33: 113-118.

[49] Trail M, Nelson N, Van JN, Appel SH, Lai EC. Major stressors facing patients with amyotrophic lateral sclerosis (ALS): a survey to identify their concerns and to compare with those of their caregivers. Amyotroph Lateral Scler Other Motor Neuron Disord 2004; 5: 40-45.

[50] Tramonti F, Barsanti I, Bongioanni P, Bogliolo C3, Rossi B. A permanent emergency: a longitudinal study on families coping with amyotrophic lateral sclerosis. Fam Syst Health 2014; 32. 271-279.

[51] Vignola A, Guzzo A, Calvo A, Moglia C, Pessia A, Cavallo E, Cammarosano S, Giacone S, Ghiglione P, Chiò A. Anxiety undermines quality of life in ALS patients and caregivers. Eur J Neurol 2008; 15: 1231-1236.

[52] Wolf J, Safer A, Wöhrle JC, Palm F, Nix WA, Maschke M, Grau AJ. Factors predicting one-year mortality in amyotrophic lateral sclerosis patients - data from a population-based registry. BMC Neurol 2014; 14: 197.

[53] Öhman M, Söderberg S. The experiences of close relatives living with a person with serious chronic illnes. Qual Health Res 2003; 14: 396-401. 